Article

\title{
Sustainable Synthesis of Epoxidized Cynara $C$. Seed Oil
}

\author{
Rosa Turco ${ }^{1, *(1)}$ and Martino Di Serio ${ }^{1,2} \mathbb{D}$ \\ 1 Department of Chemical Sciences, University of Naples Federico II, Complesso Universitario di Monte \\ Sant'Angelo, 80126 Naples, Italy; diserio@unina.it \\ 2 CIRCC - Consorzio Interuniversitario per le Reattività Chimiche e la Catalisi, via C. Ulpiani 27, \\ 70126 Bari, Italy \\ * Correspondence: rosa.turco@unina.it; Tel.: +39-081674011
}

Received: 19 May 2020; Accepted: 23 June 2020; Published: 27 June 2020

check for updates

\begin{abstract}
The use of non-edible vegetable oils to produce oleochemicals has been attracting more attention in recent years. Cardoon seed oil, derived from the Cynara C. plant, growing in marginal and contaminated lands, represents a non-edible alternative to soybean oil to obtain plasticizers through epoxidation reaction. The use of hydrogen peroxide as oxidant and in the presence of a heterogeneous catalyst allows overcoming the limits of epoxidation with peracids. $\gamma$-alumina has been shown to have an active catalyst epoxidation reaction with hydrogen peroxide, mainly using acetonitrile as solvent. However, the use of acetonitrile as solvent is widely debated due to its hazardous character and health issues. For these reasons, the influence of solvent on the reaction was studied in this work to find a more environmentally friendly and stable solvent. The study showed that the epoxidation reaction takes place also in the absence of solvent although with lower selectivity. The type of solvent influences both the epoxidation and decomposition reactions of hydrogen peroxide. $\gamma$-valerolactone was found to be the most promising solvent for cardoon oil epoxidation reaction. This finding represents a noteworthy novelty in the field of epoxidation of vegetable oils with hydrogen peroxide, opening the way to greener and cleaner process. Finally, an optimization study showed that the most effective molar ratio between hydrogen peroxide and double bonds for better selectivity was 4.5 and the need to use the highest possible initial concentration of hydrogen peroxide (approximately $60 \mathrm{wt}$ \%).
\end{abstract}

Keywords: epoxidized oil; cardoon oil; alumina; oxidation; hydrogen peroxide

\section{Introduction}

The sustainable development goals (SDGs) of 2015 aim to improve global wellness by addressing social, environmental, and economical sustainability and represent imperatives that could drive industrial and academic chemical research. The link with chemical sector is demonstrated by the fact that among these, 14 require chemistry, and the term "chemicals" is explicitly expressed in SDG 12 (consumption and production), SDG 6 (water and sanitation), and SDG 3 (healthy lives and well-being). Therefore, green and sustainable chemistry could be some valid tools in the achievement of SDG purposes [1]. Biomass use is fundamental to respond to this demand for sustainability: in addition to meeting the need for low environmental impact, as contributing to reduce the amount of Greenhouse Gases (GHG), and low generation of waste, it offers a bridge towards economic and industrial sustainability through the development of a proper biorefinery, which allows biomass conversion into products with high added value [2,3]. Moreover, the use of biomass as renewable source meets some principles of green chemistry, and its holistic application could allow achieving the circular economy rather than the linear one. A circular economy is defined by two governing principles: maximize the 
value of resource indefinitely and minimize unrecoverable waste. For these reasons, unsustainable resource consumption, waste, and pollution need to be avoided. Biomass use allows the realization of a circular economy, after assessment by stakeholders across the value chain, from product design to waste management $[4,5]$.

Vegetable oils are one of the most promising and cheapest renewable feedstocks for bio-based material production in the chemical industry owing to the degradation and low toxicity of resulting products [6]. The main applications of oil-based products concern polymeric coatings, such as additives [7,8] and plasticizers [9], lubricants [10], emollients for cosmetic formulations, surfactants, and fuels [11]. Thanks to their versatility that allows their use in many industrial sectors, today, the demand for vegetable oils, both in terms of consumption and generation, is continuously growing. Epoxidized oils are very interesting oleochemicals; they are mainly used as polyvinyl chloride (PVC) stabilizers, plasticizers for plastics [12,13], lubricants [10], and starting materials to produce polyols and prepolymers in surface-coating formulations and to synthesize polyurethane foams [7]. Moreover, they are used as modifier thermoset polymers, such as for linoleum flooring [14]. They are considered a potential and renewable bio-based alternative to petro-based phthalates, other common PVC plasticizers. The use of phthalates is nowadays strongly debated by the international scientific community due to their toxicity issues arising from their aptitude to migration. For these reasons, some phthalates (diethylhexyl phthalate (DEHP), diisononyl phthalate (DINP), and dioctyl phthalate (DOP)) were banned in specific uses, such as in toys and healthcare supplies [15]. Epoxidized soybean oil (ESBO) is surely the most important epoxidized vegetable oil with an annual production of approximately 100 kTon [16].

Turco et al. have recently reported the possibility of replacing edible oils, such as soybean, with more sustainable ones, such as cardoon oil, resolving in this way also the food-non-food debate raised by environmentalists on the extensive consumption of vegetable oils for non-food purposes, especially in poor and developing countries [17].

Non-edible oils are not suitable for human food due to the presence of some toxic components in the oils [18], and they are expected to employ lands that are largely unproductive, poverty areas, and degraded forests.

Cynara cardunculus L. or cardoon is a Mediterranean-region-native plant, which adapts to grow on arid and contaminated lands and in harsh habitat conditions (high temperature, salinity, and drought). This plant can be considered as an oil crop [19,20]; it has been estimated to produce a seed yield of approximately $1.36 \mathrm{t} \mathrm{ha}^{-1} \mathrm{y}^{-1}$, with content at $25 \mathrm{wt}$. \%, characterized by a composition similar to that of soybean [20]. For these reasons, cardoon has been attracting an increasing interest in both academic and industrial research for several applications [21,22], and it has been proposed as potential substitute of soybean oil.

Today, epoxidized soybean oil is industrially produced by batch reactor according to the classical method via Prileschajew reaction, by using peracids. In this path, the unsaturated fragments of oil react with peracids generated in situ, for safety reasons, by the acid-catalyzed oxidation of the corresponding organic acid with hydrogen peroxide. The peracid formation occurs in aqueous phase in the presence of soluble mineral acids as catalysts, then the obtained peracid migrates into the oil-immiscible phase, giving the epoxidation reaction. However, many problems are drawn from the aforesaid process, such as low epoxide selectivity, corrosion of equipment, and complicated downstream procedures of separation and recovery of the final product. Recently, many solutions have been proposed to make the epoxidation process more sustainable, such as by the substitution of homogeneous acid catalyst with a heterogeneous one (exchange resins [17,23-25], zeolites [12]) or by direct use of hydrogen peroxide instead of peracids with heterogeneous catalysts, such as titanium-silica oxides [26] and niobium oxide-based solids [27-29].

Recently, $\gamma$-alumina was described as being a cost-effective and active catalyst for epoxidation of vegetable oils and their derivates with hydrogen peroxide [17,30-33], mainly using acetonitrile as 
solvent [30]. $\gamma$-alumina was found to be able to activate the hydrogen peroxide for the oxidation, through the formation of a peroxide site [30-32].

However, solvents have received much attention in the field of green chemistry due to restrictive legislation and evolving attitudes towards environmental issues [34], and acetonitrile is not considered a green solvent $[35,36]$, mainly raising health issues.

In light of these considerations, this work aimed at finding a greener solvent capable of replacing acetonitrile in these processes, while maintaining satisfactory results in terms of oxirane yield. For this purpose, a study of the performances of different solvents (acetonitrile, ethyl levulinate, $\gamma$-valerolactone and ethyl acetate) was carried out. Together with the epoxidation reaction, the influence on hydrogen peroxide decomposition was also evaluated. $\gamma$-valerolactone was found to be the most promising solvent for cardoon oil epoxidation reaction. Finally, by using $\gamma$-valerolactone as solvent, the effect of the concentration of the reagents was investigated to identify the optimal conditions that would allow to optimize the epoxy yields and improve the sustainability of the process.

\section{Results and Discussion}

Acetonitrile is a dipolar aprotic solvent and possesses a strong dipole moment. Among all the types of solvents, the dipolar aprotic media feature major issues. This class of solvents is very useful to chemists, but today, they are under strict environment, health, and safety regulations due to their toxicity and environmental impact [36]. Starting from these considerations, in this work, some solvents are evaluated aiming to find a more sustainable alternative to acetonitrile. In Table 1, the solvents investigated in this work are resumed.

Table 1. List of solvent investigated in this work and their physical and chemical properties $[37,38]$.

\begin{tabular}{|c|c|c|c|c|c|c|c|c|}
\hline Solvent & Acr. & Formula & $\begin{array}{l}M W(\mathrm{~g} \\
\left.\mathrm{mol}^{-1}\right)\end{array}$ & $\begin{array}{c}B P^{(a)} \\
(\mathrm{K})\end{array}$ & $\begin{array}{c}\rho^{(\mathrm{b})}(\mathrm{kg} \\
\left.\mathrm{m}^{-3}\right)\end{array}$ & $\varepsilon^{(\mathrm{c})}$ & $\begin{array}{l}\mu^{\text {(d) }} \\
\text { (D) }\end{array}$ & $\begin{array}{l}\text { Miscibility } \\
\text { with water } \\
{ }^{(e)} \\
\left(\mathrm{g} \mathrm{L}^{-1}\right)\end{array}$ \\
\hline Acetonitrile & $\mathrm{ACN}$ & $\mathrm{C}_{2} \mathrm{H}_{3} \mathrm{~N}$ & 41.05 & 355 & 780 & 37.50 & 3.44 & miscible \\
\hline Ethyl acetate & EAC & $\mathrm{C}_{4} \mathrm{H}_{8} \mathrm{O}_{2}$ & 88.11 & 350 & 901 & 6.02 & 1.78 & 85.3 \\
\hline$\gamma$-valerolactone & GVL & $\mathrm{C}_{5} \mathrm{H}_{8} \mathrm{O}_{2}$ & 100.12 & 480 & 1103 & 36.47 & 4.71 & $>100$ \\
\hline Ethyl levulinate & ELV & $\mathrm{C}_{7} \mathrm{H}_{12} \mathrm{O}_{3}$ & 144.17 & 479 & 1010 & 11.90 & 5.19 & 22.7 \\
\hline
\end{tabular}

(a) Boiling point; ${ }^{(\mathrm{b})}$ density at $20{ }^{\circ} \mathrm{C}$; (c) dielectric constant; ${ }^{(\mathrm{d})}$ dipole moment; ${ }^{(\mathrm{e})}$ data at $25^{\circ} \mathrm{C}$.

The effect on conversion and selectivity of the different solvents can be observed in Figure 1.

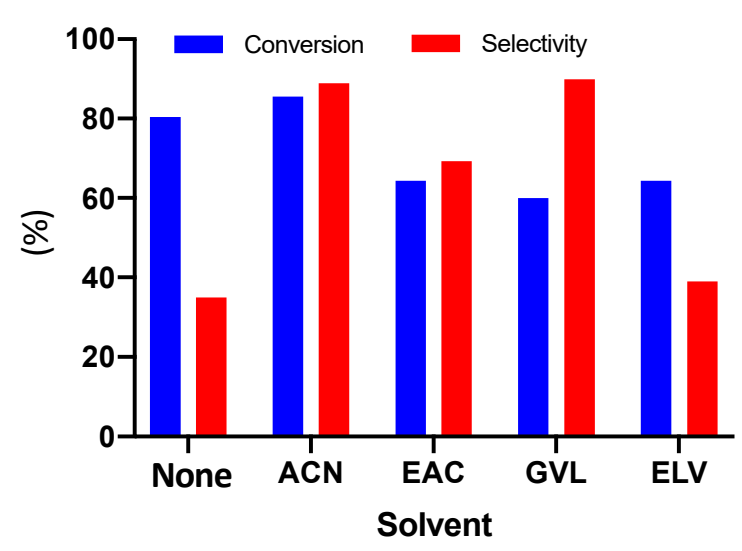

Figure 1. Conversion of double bonds (DB) and selectivity for epoxide, epoxidation, without solvent (RUN 1) and in the presence of different solvents (ACN: acetonitrile RUN 2; EAC: ethyl acetate, RUN 3; GVL: $\gamma$-valerolactone, RUN 4; ELV: ethyl levulinate, RUN 5. Experimental conditions: $600 \mathrm{mg}$ of catalyst, $6.9 \mathrm{~g}$ of $\mathrm{H}_{2} \mathrm{O}_{2}$ (60\% wt.), $5 \mathrm{~g}$ ( $0.024 \mathrm{~mol}$ of double bonds) of cardoon oil, $20 \mathrm{~cm}^{3}$ of solvent, and reaction temperature of $78-80{ }^{\circ} \mathrm{C}$. 
The solvent-free epoxidation run (RUN 1) provided a high conversion of double bonds $(80 \%)$ even if the selectivity value was very low (35\%). These results can be justified by higher concentration of hydrogen peroxide derived from the absence of a solvent. However, the yield and selectivity values were lower than epoxidation with solvents due to the acidic characteristic of hydrogen peroxide if it is specially concentrated. This acidic environment ruins the selectivity, promoting side reactions of ring-opening reactions.

The high concentration of hydrogen peroxide favors the epoxidation reaction (Figure 2).
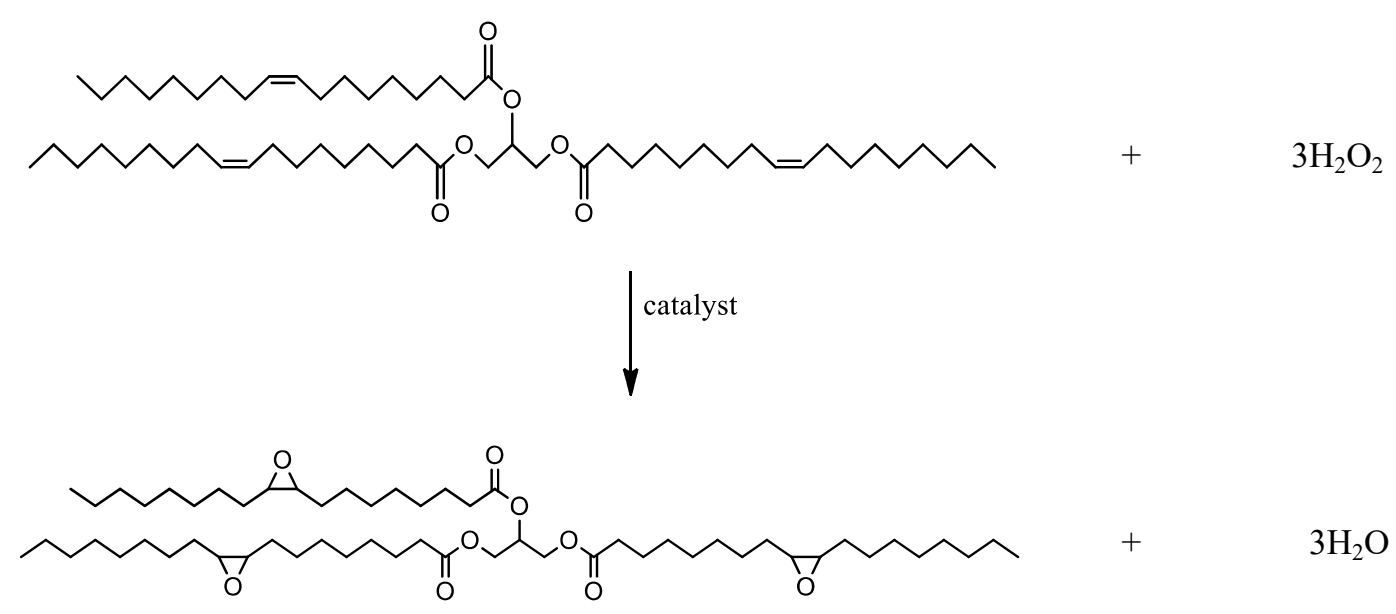

Figure 2. Epoxidation reaction with hydrogen peroxide as oxidant.

By contrast, the high concentration of water, in the presence of an acid environment, derived by the acidic characteristic of hydrogen peroxide, enhances the rate of ring-opening side reaction (Figure 3), ruining the selectivity:

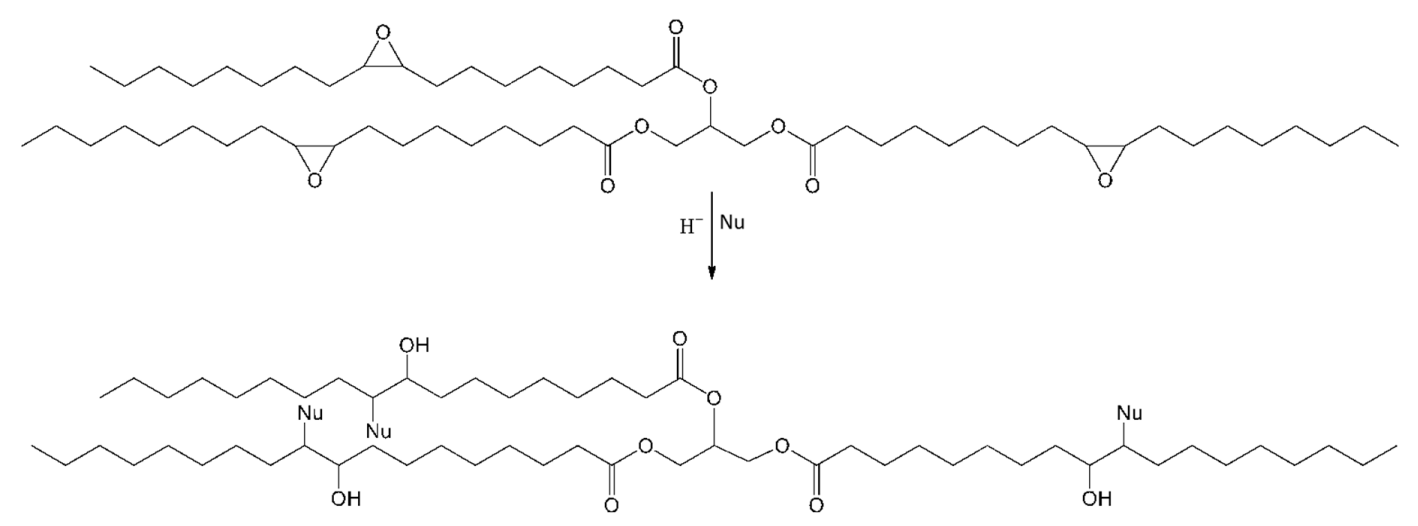

Figure 3. Ring-opening reaction of epoxides with a nucleophile $(\mathrm{Nu})$.

The presence of a solvent makes the reaction system more diluted that might preserve the degradation of the oxirane group. This is evidenced by the selectivity values found for the epoxidation runs in the presence of solvents (Figure 1). The epoxidation reactions were all performed in similar conditions, changing only the solvent type. From the results in Figure 1, the strong effect of solvent type on the epoxidation trend emerged.

The behavior of the different solvent with respect to selectivity is strictly linked with water solubility. With the increase of solubility, an increase in selectivity was observed. Ethyl acetate (EAC), ethyl levulinate (ELV), and $\gamma$-valerolactone (GVL) gave quite the same conversion of double bonds $(60-65 \%)$ but with strong differences in selectivity GVL $>$ EAC > ELV.

Acetonitrile was confirmed as being the most efficient solvent for this reaction system: The highest conversion was achieved ( $88 \%$ ) with selectivity similar to that of GVL $(90 \%)$. In any case, the results 
obtained can be argued, taking into account the physical parameters, reported in Table 1 , of the different solvents, above all considering the dielectric constant values and the dipole moment.

The complete miscibility of acetonitrile with water, followed by $\gamma$-valerolactone, justified by the highest values of $\varepsilon$ and $\mu$ with respect to the other two solvents, allows explaining the better results obtained.

In particular, while the oil is miscible in all solvents, hydrogen peroxide and water are completely soluble in acetonitrile and $\gamma$-valerolactone, and only partially in esters [33]. Moreover, the lower selectivity found when ethyl acetate as solvent was employed can be explained, assuming the presence of acetic acid, produced by hydrolysis of ethyl acetate. This acid promotes the degradation of oxirane groups by a ring-opening reaction [19].

In addition to the degradation reactions of oxirane group, the side reaction of decomposition of hydrogen peroxide should be considered [39]. Hydrogen peroxide is the oxidizing species, which reacts with the active sites to form the hydroperoxide groups, subsequently saturating the double bonds with the formation of oxirane. Hence, the concentration of the latter is expected to significantly influence the course of the reaction.

Turco et al. had demonstrated, in accordance with Van Vliet [40], that alumina not only acts as an epoxidation catalyst but also promotes the decomposition of hydrogen peroxide.

$\gamma$-alumina is characterized by a very complicated surface, with the presence of different Lewis centers, for the type and strength, corresponding to coordinatively unsaturated aluminum ions and hydroxyl groups. The epoxidation reaction was believed to occur on the surface of alumina by the formation of hydroperoxide species, involving weak Lewis acid sites, consisting in five-coordinate $\mathrm{Al}^{3+}$. Strong and medium Lewis acid sites, by contrast, were involved in undesired side reactions, such as the ring opening of the epoxides and the decomposition of hydrogen peroxide.

Furthermore, according to [41], different solvents that dissolve hydrogen peroxide better or worse could contribute to decomposition. To clarify this effect, appropriate decomposition runs were carried out, bringing together hydrogen peroxide, solvent, and catalyst, according to the ratios used in epoxidation, in the absence of oil. The results are shown in Figure 4.

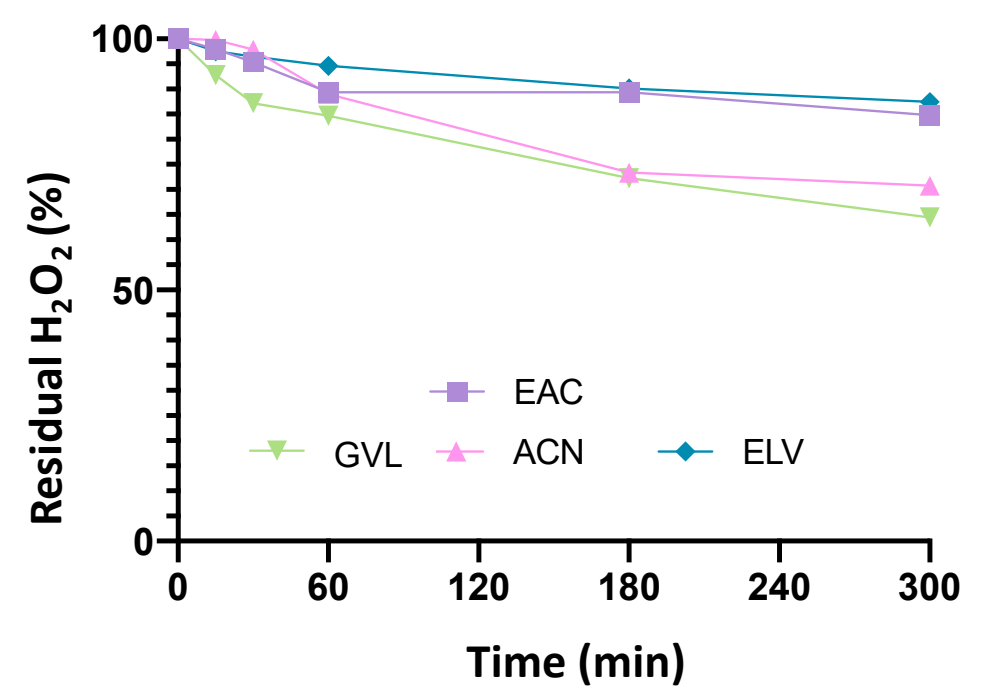

Figure 4. Residual hydrogen peroxide values for decomposition runs in the presence of different solvents. Experimental conditions: $600 \mathrm{mg}$ of catalyst, $6.9 \mathrm{~g}$ of $\mathrm{H}_{2} \mathrm{O}_{2}\left(60 \% \mathrm{wt}\right.$.), $20 \mathrm{~cm}^{3}$ of solvent, and reaction temperature of $78-80{ }^{\circ} \mathrm{C}$.

From the results of Figure 4, it is clear that the use of acetonitrile and $\gamma$-valerolactone gave almost similar results of decomposition of hydrogen peroxide ( $20 \%$ of hydrogen peroxide decomposition at $300 \mathrm{~min}$ ). In the presence of esters as solvents (acetate and ethyl levulinate), which poorly dissolve 
hydrogen peroxide, the decomposition reaction would seem to be milder or almost zero $(10 \%$ of hydrogen peroxide decomposition at $300 \mathrm{~min}$ ) [19].

Therefore, taking into account the epoxidation and decomposition results, $\gamma$-valerolactone seemed to be the most interesting solvent to replace acetonitrile in the epoxidation of cardoon oil. For this reason, the optimization of the reaction conditions, using GVL as a solvent, was evaluated. In particular, the influence of reactant concentration was investigated (RUN 3, RUNS 6-9).

In Figure 5, the conversion and epoxide selectivity values, related to RUNS 4, 6, and 7 are shown.

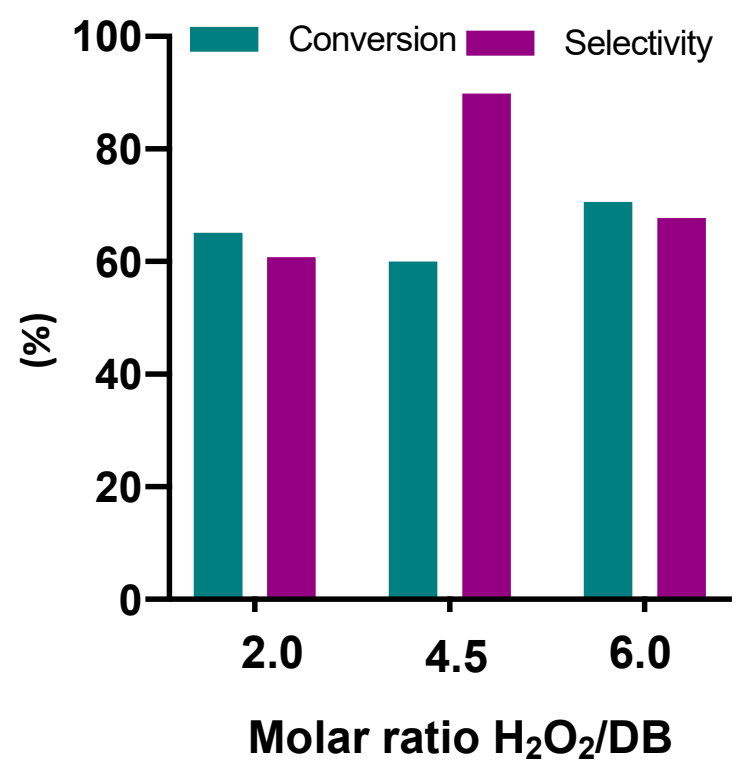

Figure 5. Conversion of double bonds (DB) and selectivity for epoxide, epoxidation, and different molar ratios of reactants. Experimental conditions: $600 \mathrm{mg}$ of catalyst, $5 \mathrm{~g}$ ( $0.024 \mathrm{~mol}$ of double bonds) of cardoon oil, $20 \mathrm{~cm}^{3}$ of solvent, and reaction temperature of $78-80{ }^{\circ} \mathrm{C}$.

Different results in epoxidation were observed by varying the molar ratio between hydrogen peroxide and oil unsaturation. Taking into account both the conversion and the selectivity values reached, the best molar ratio seemed to be 4.5. To explain this behavior, it is necessary to consider the contribution of both the main and secondary reactions (epoxy degradation). An increment in hydrogen peroxide/double bond molar ratio produced an increase of the epoxidation reaction rate, and the secondary reactions also raised the water concentration, therefore ruining the selectivity with epoxy degradation. These results are in agreement with the literature $[40,42]$, where the pivotal role of the water amount on the epoxidation rate is pointed out. Actually, a small amount of water is necessary to rehydrate the surface, indispensable for the activity of alumina in this reaction. However, an excessive quantity of water, derived by the reaction and the use of dilute hydrogen peroxide, diminishes the selectivity to the desired epoxides.

The need to use a high concentration of hydrogen peroxide is demonstrated by the results reported in Figure 6 (RUN 3, RUN 8, and RUN 9). The use of more diluted hydrogen peroxide produced a decrease of double bond conversion but also of selectivity. The observed phenomenon is in agreement with the previous results where the influence of water on degradation reaction was pointed out. 


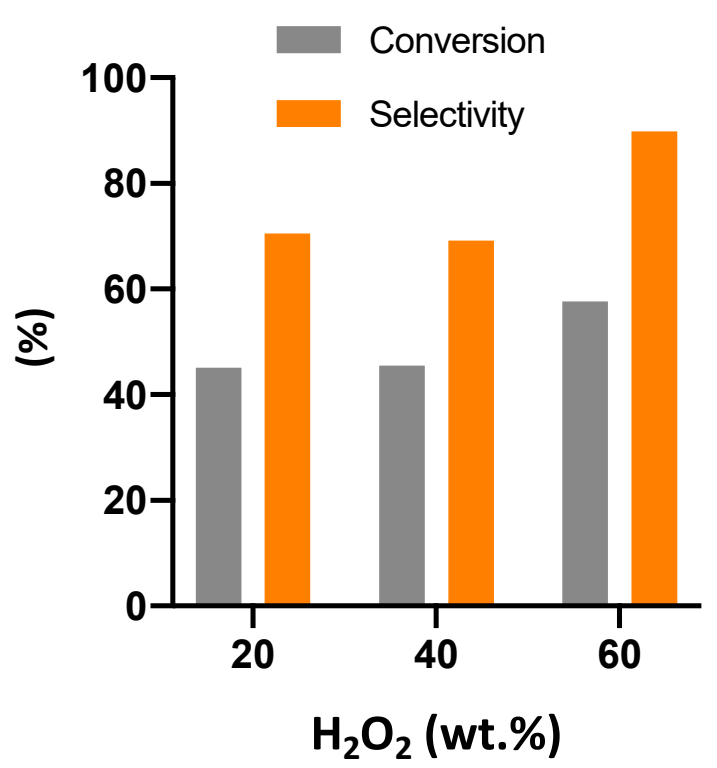

Figure 6. Conversion of double bonds (DB) and selectivity for epoxide for epoxidation in the presence of different initial concentrations of $\mathrm{H}_{2} \mathrm{O}_{2}$. Experimental conditions: $600 \mathrm{mg}$ of catalyst, $5 \mathrm{~g}(0.024 \mathrm{~mol}$ of double bonds) of cardoon oil, reactants molar ratio of $4.5,20 \mathrm{~cm}^{3}$ of solvent, and reaction temperature of $78-80^{\circ} \mathrm{C}$.

As can be seen from Figure 6, working with a more concentrated hydrogen peroxide and keeping constant the molar ratio between reactants $\left(\mathrm{H}_{2} \mathrm{O}_{2} / \mathrm{DB}\right.$ of 4.5), optimum values can be achieved both in conversion and selectivity. This finding can be ascribed to an increase of reaction rate with a minimization of the contribution of the secondary reactions of the ring opening by water in the acidic environment.

\section{Materials and Methods}

\subsection{Materials}

The cardoon seed oil with iodine value of $125\left(\mathrm{~g}_{\mathrm{I} 2} / 100 \mathrm{~g}_{\text {sample }}\right)$ was recovered from a field experiment made in Acerra, Naples (NA), a plain area of approximately $28 \mathrm{~m}$, characterized by dry and very warm spring-summers and by sandy loam soils (clay, $14.4 \%$; silt, $22.6 \%$; and sand, $63.0 \%$ ), with a neutral $\mathrm{pH}$, and a content of $\mathrm{N}(0.2 \mathrm{wt}$. \%) and organic matter (2.6 wt. \%)). Oil was extracted with a mechanical press, with an operative capacity of $14 \mathrm{~kg} / \mathrm{h}$ and temperature regulated at $50{ }^{\circ} \mathrm{C}$. The extracted oil showed the following fatty acid composition (wt. \%): palmitic $=11.2$, stearic $=3.4$, oleic $=25.4$, linoleic $=58.7$, linolenic $=0.3$, and others $=1.0$. This composition, measured by gas-chromatographic analysis, was supplied by INNOVHUB-SSOG.

Commercial alumina was supplied by Sasol, and it was used as received without further purification (phase $\gamma$; specific area, $200 \mathrm{~m}^{2} \mathrm{~g}^{-1}$; pore volume, $0.37 \mathrm{~cm}^{3} \mathrm{~g}^{-1}$ ). Hydrogen peroxide (60 wt. \%) was kindly provided by Solvay Italia. Ethyl acetate (99.5 wt. \%), acetonitrile (99.9 wt. \%), ethyl levulinate (99 wt. \%), $\gamma$-valerolactone (99 wt. \%), and all the other chemicals were purchased from Merck at the highest level of purity available and used as received without further purification.

\subsection{Experimental Runs}

The runs were carried out in a laboratory-scale reactor, consisting of a three-necked round-bottom glass batch reactor, heated in an oil bath, equipped with a condenser, a thermometer, and a magnetic bar for vigorous stirring. Several decomposition and epoxidation runs were performed; they differ for one or more operative variables, such as solvent and molar ratio between reagents. The hydrogen peroxide 
used was of 60 wt. \% unless otherwise specified. The standard deviations relative to conversion and selectivity values were $2.8 \%$ and $1.8 \%$, respectively.

\subsubsection{Hydrogen Peroxide Decomposition Runs}

For the decomposition tests, $20 \mathrm{~cm}^{3}$ of a certain solvent was added to the three-necked $100 \mathrm{~mL}$ glass flask. Subsequently, $6.9 \mathrm{~g}$ of $\mathrm{H}_{2} \mathrm{O}_{2}$ was added. After the addition of the magnetic bar, the glass flask was connected to the condenser, placed in an oil bath, and upon reaching the temperature of $80{ }^{\circ} \mathrm{C}, 600 \mathrm{mg}$ of $\gamma$-alumina was added. After adding the catalyst, the system is kept isothermal at a temperature of $80^{\circ} \mathrm{C}$ for $5 \mathrm{~h}$. Several withdrawals were taken from the reaction system at different times. The process was immediately quenched in an ice bath to cool and centrifuged for $10 \mathrm{~min}$ at $30 \mathrm{rpm}$. The concentration of hydrogen peroxide was determined by iodometric titration according to [43], by reacting with $\mathrm{KI}$ in a $\mathrm{H}_{2} \mathrm{SO}_{4}$ solution (2 M), and titrating with $0.1 \mathrm{~N} \mathrm{Na}_{2} \mathrm{SO}_{4}$, in the presence of starch as indicator.

The results can be expressed in terms of grams of hydrogen peroxide, using the following Equation (1):

$$
\mathrm{g}_{\mathrm{H} 2 \mathrm{O} 2}=\frac{\mathrm{N}_{\mathrm{tit}} \mathrm{V}_{\mathrm{tit}} \mathrm{M}_{\mathrm{H} 2 \mathrm{O} 2}}{2}
$$

where $N_{t i t}$ is the titrating solution normality, $V_{t i t}$ is the volume (L) of titrant, and $M_{\mathrm{H} 2 \mathrm{O} 2}\left(\mathrm{gmol}^{-1}\right)$ is the molecular weight of hydrogen peroxide.

\subsubsection{Cardoon Seed Oil Epoxidation Runs}

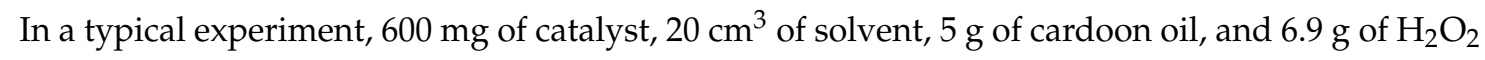
were used (unless otherwise specified). In this case, the molar ratio between oxidant and double bonds is approximately 4.5 . The temperature was kept constant $\left(78-80^{\circ} \mathrm{C}\right)$. All the reagents were added in one pot at the beginning of the reaction. Each test lasted $5 \mathrm{~h}$. At the end of each experiment, the solution was separated from the catalyst by decantation, and then analyzed to evaluate both iodine number and oxirane number to determine the double bond conversion and oxirane yield.

In Table 2, all epoxidation performed runs are reported. The same Sasol alumina previously described was used as catalyst [30].

Table 2. Epoxidation runs *.

\begin{tabular}{ccccc}
\hline RUN & Solvent & $\left.\mathbf{H}_{\mathbf{2}} \mathbf{O}_{\mathbf{2}} \mathbf{( 6 0} \mathbf{w t .} \mathbf{\%}\right) \mathbf{( g )}$ & $\mathbf{H}_{\mathbf{2}} \mathbf{O} \mathbf{( g )}$ & $\mathbf{H}_{\mathbf{2}} \mathbf{O}_{\mathbf{2}} / \mathbf{D B}$ \\
\hline 1 & - & 6.90 & - & 4.5 \\
2 & ACN & 6.90 & - & 4.5 \\
3 & EAC & 6.90 & - & 4.5 \\
4 & GVL & 6.90 & - & 4.5 \\
5 & ELV & 6.90 & - & 4.5 \\
6 & GVL & 3.03 & - & 2.0 \\
7 & GVL & 9.08 & - & 6.0 \\
8 & GVL & 6.90 & 3.50 & 4.5 \\
9 & GVL & 6.90 & 13.60 & 4.5
\end{tabular}

* Experimental conditions: $5 \mathrm{~g}$ of cardoon oil ( $0.024 \mathrm{~mol}$ of double bonds, DB), $20 \mathrm{~cm}^{3}$ of solvent, $600 \mathrm{mg}$ of $\gamma$-alumina, and reaction temperature of $78-80^{\circ} \mathrm{C}$.

The iodine value (I.V., expressed as grams of $\mathrm{I}_{2}$ per $100 \mathrm{~g}$ of sample) was determined according to the standard NP-941 (1972) [44]. The fatty acid composition was determined by gas chromatography, as Fatty Acid Methyl Ester (FAME), following the methodology described in ISO 12966-4:2005 and ISO 12966-2:2017 [45].

The oxirane number (O.N. expressed as grams of oxirane oxygen per $100 \mathrm{~g}$ of sample) was measured according to standard ASTM D1652-97 [46], using cetyltrimethylammonium bromide (CTAB) dissolved in glacial acetic acid and perchloric acid solution $(0.1 \mathrm{~N})$ for potentiometric titration. 
The determination of I.V and O.N. allowed to calculate the double bond conversion, as shown in Equation (2):

$$
\text { Conversion }(\%)=\frac{[\mathrm{I} . \mathrm{V} \cdot]_{\mathrm{i}}-[\mathrm{I} . \mathrm{V} .]_{\mathrm{f}}}{[\mathrm{I} . \mathrm{V} .]_{\mathrm{i}}} \times 100
$$

and the epoxide yield, as shown in Equation (3):

$$
\operatorname{Yield}(\%)=\frac{[\mathrm{O} . \mathrm{N} \cdot]_{\mathrm{f}} \times \mathrm{MW}_{\mathrm{I}_{2}}}{[\mathrm{I} . \mathrm{V} \cdot]_{\mathrm{i}} \times \mathrm{MW}_{\mathrm{O}}} \times 100
$$

where the suffixes $i$ and $f$ stand for initial and final, while $\mathrm{MW}_{\mathrm{I} 2}$ and $\mathrm{MW}_{\mathrm{O}}$ refer to molecular weight of iodine and oxygen, respectively.

The ratio between yield and conversion gave the process selectivity (\%), as shown in Equation (4):

$$
\text { Selectivity }(\%)=\frac{\text { Yield }}{\text { Conversion }} \times 100
$$

\section{Conclusions}

In this work, the influence of the type of solvent on the epoxidation reaction of cardoon oil with hydrogen peroxide was confirmed. The possibility of conducting the reaction was evaluated even in the absence of a solvent; however, at the expense of selectivity. $\gamma$-valerolactone was found to be the green alternative to acetonitrile. Like acetonitrile, $\gamma$-valerolactone is capable of dissolving both oil and hydrogen peroxide, resulting in optimal reaction yields. Process optimization showed that the most effective molar ratio, between hydrogen peroxide and double bonds, for better selectivity was 4.5 . Moreover, the study evidenced that it is necessary to apply the highest possible initial concentration of hydrogen peroxide (about $60 \mathrm{wt}$. \%) to guarantee not only high conversion values, but at the same time preserve the selectivity with epoxide at acceptable values $(>70 \%)$.

Author Contributions: In this paper, all authors synergistically assisted in the main steps of the research, leading to the final version of the manuscript. Anyway, specific but not unique outlines of their roles can be provided. R.T.: Corresponding author, project administration, conceptualization, investigation, writing-original draft preparation. M.D.S.: supervision, project administration, conceptualization, Writing-review \& editing, funding acquisition. All authors have read and agreed to the published version of the manuscript.

Funding: This research was funded by PRIN grant: Progetti di Ricerca di Interesse Nazionale-Bando 2017- “CARDoon valorisation by InteGrAted biorefiNery (CARDIGAN)" of Italian Ministero dell'Istruzione dell'Università e della Ricerca for the financial support [COD. 2017KBTK93].

Acknowledgments: The authors are grateful to Solvay Italy for having provided hydrogen peroxide and Massimo Fagnano for the cardoon seed oil.

Conflicts of Interest: The authors declare no conflict of interest.

\section{References}

1. Chen, T.-L.; Kim, H.; Pan, S.-Y.; Tseng, P.-C.; Lin, Y.-P.; Chiang, P.-C. Implementation of green chemistry principles in circular economy system towards sustainable development goals: Challenges and perspectives. Sci. Total Environ. 2020, 716, 136998. [CrossRef] [PubMed]

2. Hassan, S.; Williams, G.A.; Jaiswal, A.K. Moving towards the second generation of lignocellulosic biorefineries in the EU: Drivers, challenges, and opportunities. Renew. Sustain. Energy Rev. 2019, 101, 590-599. [CrossRef]

3. Bakshi, B.R. Toward sustainable chemical engineering: The role of process systems engineering. Annu. Rev. Chem. Biomol. Eng. 2019, 10, 265-288. [CrossRef] [PubMed]

4. Halpaap, A.; Dittkrist, J. Sustainable chemistry in the global chemicals and waste management agenda. Curr. Opin. Green Sustain. Chem. 2018, 9, 25-29. [CrossRef]

5. European Commission. Towards a Circular Economy: A Zero Waste Programme for Europe. Available online: http://ec.europa.eu/environment/circular-economy/index_en.htm (accessed on 24 March 2019).

6. Biermann, U.; Bornscheuer, U.T.; Meier, M.A.R.; Metzger, J.O.; Schäfer, H.J. Oils and fats as renewable raw materials in chemistry. Angew. Chem. Int. Ed. 2011, 50, 3854-3871. [CrossRef] 
7. Petrović, Z.S. Polyurethanes from vegetable oils. Polym. Rev. 2008, 48, 109-155. [CrossRef]

8. Benessere, V.; Cucciolito, M.E.; De Santis, A.; Di Serio, M.; Esposito, R.; Ruffo, F.; Turco, R. Sustainable process for production of azelaic acid through oxidative cleavage of oleic acid. J. Am. Oil Chem. Soc. 2015, 92, 1701-1707. [CrossRef]

9. Huang, X.; Yang, X.; Liu, H.; Shang, S.; Cai, Z.; Wu, K. Bio-based thermosetting epoxy foams from epoxidized soybean oil and rosin with enhanced properties. Ind. Crops Prod. 2019, 133, 111540. [CrossRef]

10. Karmakar, G.; Ghosh, P.; Sharma, B.K. Chemically modifying vegetable oils to prepare green lubricants. Lubricants 2017, 5, 44. [CrossRef]

11. Lligadas, G.; Ronda, J.C.; Galia, M.; Cadiz, V. Renewable polymeric materials from vegetable oils: A perspective. Mater. Today 2013, 16, 337-343. [CrossRef]

12. Turco, R.; Pischetola, C.; Di Serio, M.; Vitiello, R.; Tesser, R.; Santacesaria, E. Selective epoxidation of soybean oil in the presence of h-y zeolite. Ind. Eng. Chem. Res. 2017, 56, 7930-7936. [CrossRef]

13. Hosney, H.; Nadiem, B.; Ashour, I.; Mustafa, I.; El-Shibiny, A. Epoxidized vegetable oil and bio-based materials as PVC plasticizer. J. Appl. Polym. Sci. 2018, 135, 46270. [CrossRef]

14. Pérez-Sena, W.Y.; Salmi, T.; Estel, L.; Leveneur, S. Thermal risk assessment for the epoxidation of linseed oil by classical Prisleschajew epoxidation and by direct epoxidation by $\mathrm{H}_{2} \mathrm{O}_{2}$ on alumina. J. Therm. Anal. Calorim. 2019, 140, 673-684. [CrossRef]

15. Lyche, J.L. Phthalates. In Reproductive and Developmental Toxicology, 2nd ed.; Gupta, R.C., Ed.; Academic Press: Cambridge, MA, USA, 2017; pp. 829-856.

16. Grand Review Research, Bio-Platicizers Market and Segment Forecast to 2025 . Available online: https://www.grandviewresearch.com/press-release/global-bio-plasticizers-market (accessed on 1 May 2019).

17. Turco, R.; Tesser, R.; Russo, V.; Vitiello, R.; Fagnano, M.; Di Serio, M. Comparison of different possible technologies for epoxidation of Cynara cardunculus seed oil. Eur. J. Lipid Sci. Technol. 2019, 122. [CrossRef]

18. Demirbas, A. Potential resources of non-edible oils for biodiesel. Energy Sources Part B Econ. Plan. Policy 2009, 4, 310-314. [CrossRef]

19. Gominho, J.; Curt, M.D.; Lourenço, A.; Fernández, J.; Pereira, H. Cynara cardunculus L. as a biomass and multi-purpose crop: A review of 30 years of research. Biomass Bioenergy 2018, 109, 257-275. [CrossRef]

20. Torres, C.M.; Rios, S.D.; Torras, C.; Salvadó, J.; Mateo-Sanz, J.M.; Jiménez, L. Sustainability analysis of biodiesel production from Cynara Cardunculus crop. Fuel 2013, 111, 535-542. [CrossRef]

21. Toscano, V.; Sollima, L.; Genovese, C.; Melilli, M.; Raccuia, S.A. Pilot plant system for biodiesel and pellet production from cardoon: Technical and economic feasibility. Acta Hortic. 2016, 429-442. [CrossRef]

22. Raccuia, S.A.; Melilli, M.G. Cynara cardunculus L., a potential source of inulin in the Mediterranean environment: Screening of genetic variability. Aust. J. Agric. Res. 2004, 55, 693-698. [CrossRef]

23. Goud, V.V.; Patwardhan, A.V.; Dinda, S.; Pradhan, N.C. Kinetics of epoxidation of jatropha oil with peroxyacetic and peroxyformic acid catalysed by acidic ion exchange resin. Chem. Eng. Sci. 2007, 62, 4065-4076. [CrossRef]

24. Di Serio, M.; Russo, V.; Santacesaria, E.; Tesser, R.; Turco, R.; Vitiello, R. Liquid-liquid-solid model for the epoxidation of soybean oil catalyzed by amberlyst-16. Ind. Eng. Chem. Res. 2017, 56, 12963-12971. [CrossRef]

25. Aguilera, A.F.; Tolvanen, P.; Oger, A.; Eränen, K.; Leveneur, S.; Mikkola, J.; Salmi, T. Screening of ion exchange resin catalysts for epoxidation of oleic acid under the influence of conventional and microwave heating. J. Chem. Technol. Biotechnol. 2019, 94, 3020-3031. [CrossRef]

26. Guidotti, M.; Gavrilova, E.; Galarneau, A.; Coq, B.; Psaro, R.; Ravasio, N. Epoxidation of methyl oleate with hydrogen peroxide. The use of Ti-containing silica solids as efficient heterogeneous catalysts. Green Chem. 2011, 13, 1806-1811. [CrossRef]

27. Turco, R.; Aronne, A.; Carniti, P.; Gervasini, A.; Minieri, L.; Pernice, P.; Tesser, R.; Vitiello, R.; Di Serio, M. Influence of preparation methods and structure of niobium oxide-based catalysts in the epoxidation reaction. Catal. Today 2015, 254, 99-103. [CrossRef]

28. Turco, R.; Vitiello, R.; Vergara, A.; Di Serio, M.; Tesser, R.; Andini, S. Niobium Based Catalysts for Methyl Oleate Epoxidation Reaction. Top. Catal. 2017, 36, 1054-1061. [CrossRef]

29. Scotti, N.; Ravasio, N.; Evangelistib, C.; Psaro, R.; Penso, M.; Niphadkar, P.S.; Bokade, V.V.; Guidotti, M. Epoxidation of Karanja (Millettia pinnata) oil methyl esters in the presence of hydrogen peroxide over a simple niobium-containing catalyst. Catalysts 2019, 9, 344. [CrossRef] 
30. Turco, R.; Pischetola, C.; Di Serio, M.; Tesser, R.; Andini, S. New findings on soybean and methylester epoxidation with alumina as the catalyst. RSC Adv. 2016, 6, 31647-31652. [CrossRef]

31. Sepulveda, J.; Teixeira, S.; Schuchardt, U. Alumina-catalyzed epoxidation of unsaturated fatty esters with hydrogen peroxide. Appl. Catal. A Gen. 2007, 318, 213-217. [CrossRef]

32. Rinaldi, R.; Fujiwara, F.Y.; Holderich, W.; Schuchardt, U. Tuning the acidic properties of aluminas via sol-gel synthesis: New findings on the active site of alumina-catalyzed epoxidation with hydrogen peroxide. J. Catal. 2006, 244, 92-101. [CrossRef]

33. Suarez, P.A.Z.; Pereira, M.S.C.; Doll, K.M.; Sharma, B.K.; Erhan, S.Z. Epoxidation of methyl oleate using heterogeneous catalyst. Ind. Eng. Chem. Res. 2009, 48, 3268-3270. [CrossRef]

34. Byrne, F.; Jin, S.; Paggiola, G.; Petchey, T.H.M.; Clark, J.H.; Farmer, T.J.; Hunt, A.J.; McElroy, C.R.; Sherwood, J. Tools and techniques for solvent selection: Green solvent selection guides. Sustain. Chem. Process. 2016, 4. [CrossRef]

35. Henderson, R.K.; Jiménez-González, C.; Constable, D.J.C.; Alston, S.R.; Inglis, G.G.A.; Fisher, G.; Sherwood, J.; Binks, S.P.; Curzons, A.D. Expanding GSK's solvent selection guide-Embedding sustainability into solvent selection starting at medicinal chemistry. Green Chem. 2011, 13, 854-862. [CrossRef]

36. Prat, D.; Pardigon, O.; Flemming, H.-W.; Letestu, S.; Ducandas, V.; Isnard, P.; Guntrum, E.; Senac, T.; Ruisseau, S.; Cruciani, P.; et al. Sanofi's solvent selection guide: A step toward more sustainable processes. Org. Process Res. Dev. 2013, 17, 1517-1525. [CrossRef]

37. Lomba, L.; Giner, B.; Bandrés, I.; Lafuente, C.; Pino-Otín, M.R. Physicochemical properties of green solvents derived from biomass. Green Chem. 2011, 13, 2062. [CrossRef]

38. Available online: https://people.chem.umass.edu/xray/solvent.html (accessed on 6 June 2020).

39. Russo, V.; Protasova, L.; Turco, R.; De Croon, M.H.J.M.; Hessel, V.; Santacesaria, E. Hydrogen peroxide decomposition on manganese oxide supported catalyst: From batch reactor to continuous microreactor. Ind. Eng. Chem. Res. 2013, 52, 7668-7676. [CrossRef]

40. Van Vliet, M.C.A.; Mandelli, D.; Arends, I.W.C.E.; Schuchardt, U.; Sheldon, R.A. Alumina: A cheap, active and selective catalyst for epoxidations with (aqueous) hydrogen peroxide. Green Chem. 2001, 3, 243-246. [CrossRef]

41. Corma, A.; Esteve, P.; Martínez, A. Solvent effects during the oxidation of olefins and alcohols with hydrogen peroxide on Ti-Beta catalyst: The influence of the hydrophilicity-hydrophobicity of the zeolite. J. Catal. 1996, 161, 11-19. [CrossRef]

42. Knozinger, H. Advances in Catalysis; Accademic Press: New York, NY, USA, 1976; p. 25.

43. Kolthoff, I.M.; Sandell, E.B.; Meehan, E.J. Treatise on Analytical Chemistry; John Wiley \& Sons: New York, NY, USA, 1993; Volume 2, p. 888.

44. International Organization for Standardization. Animal and Vegetable Fats and Oils_Determination of Iodine Value; ISO: Geneva, Switzerland, 2018; ISO 3961:2018.

45. International Organization for Standardization. Animal and Vegetable Fats and Oils—Gas Chromatography of Fatty Acid Methyl Esters; ISO: Geneva, Switzerland, 2017; ISO 12966-4:2005/ISO 12966-2:2017.

46. ASTM International. Standard Test Methods for Epoxy Content of Epoxy Resins; ASTM: West Conshohocken, PA, USA, 1997; ASTM D1652-97.

(C) 2020 by the authors. Licensee MDPI, Basel, Switzerland. This article is an open access article distributed under the terms and conditions of the Creative Commons Attribution (CC BY) license (http://creativecommons.org/licenses/by/4.0/). 